\title{
DETERMINATION OF INSOLUBLE MATTER IN SHELLAC
}

\author{
By C. C. Hartman
}

\section{ABSTRACT}

In existing specifications for shellac, the insoluble content is generally defined as that portion wbich is insoluble in hot 95 per cent ethyl alcohol, denatured with methyl alcohol. The standard methods now employed are shown to give erroneous results, caused by $(a)$ incomplete solubility of the shellac wax in hot 95 per cent alcohol, (b) possible loss of fine particles of insoluble matter, and (c) retention of some of the solvent by the filter medium.

Butanol (normal butyl alcohol) and ethylene glycol-monothyl ether (cellosolve) are shown to be more satisfactory solvents for both the shellac resin and shellac wax than 95 per cent denatured alcohol. A glass-filter crucible with a disk of filter paper and an asbestos mat is a more satisfactory and efficient filtering medium than a paper extraction thimble or a series of cotton pads.

A new method is proposed in which a filter crucible and either butanol or cellosolve are used. This method is simple and rapid and yields reproducible and accurate results.

\section{CONTENTS}

I. Introduction

II. Principles of analytical methods

1. Requirements .

2. Choice of solvents.... 1106

3. Methods of extraction

(a) Continuous type

(b) Single extraction and filtration type........... 1108

III. Comparison of methods . .

1108

IV. Effect of sampling and grinding

1. Description of solvents, apparatus, and procedure

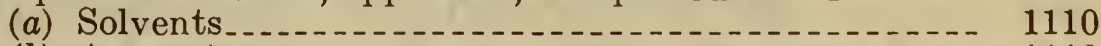

(b) Apparatus............. 1110

(c) Procedure..... 1111

2. Typical results

VI. Conclusions_...

1112

VII. Acknowledgements . .

\section{INTRODUCTION}

Lac resin, a secretion of the insect Tachardia lacca, is marketed under various trade names which signify the type and quality of the material. The main groups are known as stick lac, seed lac, garnet lac, button lac, flake shellac, and bleached shellac.

Stick lac represents the lac resin as it is stripped from the branches of the "host" tree. Seed lac is prepared from stick lac by crushing it into small granules, washing with dilute soda to remove a portion of the dye, and subsequently sieving to remove as much of the sticks and bark as possible. Flake shellac is a product of a crude native refining in which the melted resin is forced through cloth. The warm plastic mass is then stretched into thin sheets, which when cold are broken into fragments of different sizes. The natural coloring matter is removed by chemical treatment to produce bleached shellac. 
The various kinds of shellac are sold both in the dry form and in solution in alcohol as shellac varnish. All shellac contains some insoluble matter. This insoluble matter may be present from natural sources or from intentional adulteration. Some sticks and bark are usually introduced when the shellac is stripped from the twigs and branches. Sand, dust, and other organic or inorganic materials may be incorporated by high winds, forest fires, or parasitic insects.

Misra ${ }^{1}$ states that unscrupulous natives sometimes add shredded bark from the Babul tree, finely ground Mahua seed, rock salt, or fine sand. Arsenious sulphide is frequently added to give the shellac a lighter color.

For specification purposes, the insoluble matter should be defined as that portion insoluble in a specified solvent or solvents. Since shellac is usually sold on a specification which limits the content of insoluble matter, an accurate determination of this constituent is necessary. The present standard specifications ${ }^{2}$ define the insoluble matter as that which is insoluble in hot 95 per cent ethyl alcohol, denatured according to either formula No. $1^{3}$ or No. $30^{4}$ of the Bureau of Industrial Alcohol. Owing to the incomplete solubility of shellac wax in alcohol, ${ }^{5}$ the existing methods do not give reproducible results. This research was undertaken with the purpose of developing a more satisfactory method.

\section{PRINCIPLES OF ANALYTICAL METHODS}

\section{REQUIREMENTS}

It is essential that the method employed in this determination should be applicable to all types of lac resin. The accuracy and reproducibility may depend upon the solvent, the filtering medium, and the method and conditions of extraction. The solvent should dissolve all of the natural resin and wax. The filtering medium should permit rapid and thorough extraction of the soluble constituents and should retain all of the insoluble portion and none of the solvent. The method and conditions of extraction should be such as to insure complete extraction with a minimum of time and effort.

\section{CHOICE OF SOLVENTS}

The natural lac as secreted by the insect consists mainly of resin and wax. Gardner and Whitmore ${ }^{6}$ have shown that shellac resin is completely soluble in a number of common organic liquids, but the available literature on the solubility of shellac wax is rather indefinite. From among other investigators Stillwell ${ }^{7}$ reported the presence in shellac of about 0.5 per cent of a wax that is insoluble in hot alcohol and has a melting point of $93^{\circ} \mathrm{C}$. The difficulty with the existing methods is caused chiefly by the presence of this wax. Hence an

1 Misra, C. S., Agri. Research Inst., Pusa, Bull. No. 142, p. 54; 1923.

2 Proc. Am. Soc. Test. Materials, 29, Pt. I, p. 656; 1929. F. S. B. Specification No. TT-S-271. U. S. Shellac Importers' Association Official Method of Analysis, p. $7 ; 1929$.

3 Formula No. 1 calls for the addition of 5 gallons of wood alcohol to 100 gallons of ethyl alcohol (190 proof).

1 Formula No. 30, which calls for the addition of 10 gallons of wood alcohol to 100 gallons of ethyl alcohol (190 proof), was not used in this work.

5 The word "alcohol" will be used hereafter to denote 95 per cent ethyl alcohol denatured according to formula No. 1 .

6 Wm. H. Gardner and W. F. Whitmore, J. Ind. Eng. Chem., vol. 21, pp. 226-229; 1929

7 A. G. Stillwell, J. Ind. Eng. Chem., vol. 2, p. 420; 1930. 
effort was made to find a better solvent for the shellac wax both at high and low temperatures. In addition, such a solvent should be volatile at $105^{\circ} \mathrm{C}$., nontoxic, and readily available in a pure state.

Butanol ${ }^{8}$ (normal butyl alcohol) and ethylene glycol-monoethyl ether (cellosolve) were found to be the most satisfactory solvents. Quantitative data showed that both the shellac resin and the wax are completely soluble in each of these solvents.

The effect of temperature upon the solubility of the wax in different pure and mixed solvents was determined by measuring the "cloud point"; that is, the temperature at which the wax separated from the solvent. One gram samples from which all of the insoluble matter had been removed were placed in glass bottles, together with $100 \mathrm{ml}$. of the solvent to be tested. Each bottle was immersed in a water bath until the contents reached $78^{\circ} \mathrm{C}$., the boiling temperature of alcohol. The source of heat was then removed and the solution was allowed to cool slowly. The solutions were observed at intervals of $0.5^{\circ} \mathrm{C}$. until they became cloudy. 'The results are shown in Table 1. Duplicate determinations agreed within $\pm 0.5^{\circ} \mathrm{C}$.

TABLE 1.-Cloud point of shellac in various solvents

( $1 \mathrm{~g}$ of shellac in $100 \mathrm{ml}$ of solvent)

\begin{tabular}{|c|c|c|c|c|}
\hline \multirow{2}{*}{ Experiment No. } & Solvent & $\begin{array}{c}\text { (relative } \\
\text { volurne) }\end{array}$ & arts by & \multirow{2}{*}{$\begin{array}{l}\text { Cloud } \\
\text { point }\end{array}$} \\
\hline & Alcohol & Butanol & $\begin{array}{l}\text { Cello- } \\
\text { solve }\end{array}$ & \\
\hline $\begin{array}{l}1 \\
4 \\
5 \\
6\end{array}$ & $\begin{array}{c}1 \\
-- \\
-1 \\
1 \\
1 \\
1 \\
2\end{array}$ & $\begin{array}{r}1 \\
4 \\
3 \\
-1 \\
-1\end{array}$ & $\begin{array}{r}1 \\
4 \\
3\end{array}$ & $\begin{array}{l}{ }^{\circ} C . \\
78 \\
56 \\
65 \\
57 \\
60 \\
67 \\
69\end{array}$ \\
\hline
\end{tabular}

The solution in alcohol remained cloudy at the boiling point, while the butanol and cellosolve held the shellac wax in solution at a much lower temperature. As the last two liquids are good solvents for the shellac resin, they are superior to alcohol for the determination of insoluble matter. Both of these solvents can be recovered from the filtrates by direct distillation, and the distillates can be used again with accurate results.

\section{METHODS OF EXTRACTION}

(a) CONTINUOUS TYPE

Most of the accepted methods for determining the insoluble matter in shellac involve continuous extraction. The principal features of the methods are as follows: The method ${ }^{9}$ of the American Society for Testing Materials specifies the boiling of $5 \mathrm{~g}$ of the shellac in 100 to $120 \mathrm{ml}$ of alcohol for 30 minutes, filtration through a heated extraction thimble $(26$ by $80 \mathrm{~mm}$ ) and extraction for one hour in a

8 Normal butyl alcohol and ethylene glycol-monoethyl ether will be referred to, respectively, as butanol and cellosolre.

Proc. Am. Soc. Test. Materials, vol. 29, pt. 1, p. 656; 1929. 
siphon extractor in which the siphon is continuously surrounded by the vapors of the boiling alcohol. A metal condenser is used, and the conditions are adjusted so that the tube siphons 33 times per hour. The thimble is dried at $105^{\circ} \mathrm{C}$. and weighed. The extraction is repeated until constant weight is obtained.

The United States Shellac Importers' method ${ }^{10}$ is similar to the method of the American Society for Testing Materials, but involves the use of a glass condenser of a specified size and shape, siphoning at intervals of two minutes, and a single extraction for exactly one hour. The thimble is dried at $105^{\circ} \mathrm{C}$. to constant weight.

In the Stillwell method ${ }^{11}$ the filtering medium consists of three layers of cotton arranged on a perforated plate placed in a special type of siphon tube. The shellac is boiled in a mixture of 2 parts of alcohol and 1 part of carbon tetrachloride, filtered with suction and extracted with this mixed solvent.

\section{(b) SINGLE EXTRACTION AND FILTRATION TYPE}

If a good rapid solvent for the resin and wax is used, it should be possible to remove all of these materials in a single extraction with a considerable saving in time. Accordingly, such a method was developed for use with butanol and cellosolve. In this method a heated Jena glass-filter crucible containing a disk of filter paper and an asbestos mat is used as the filtering medium. The sample is boiled for five minutes in the solvent and filtered with suction. The crucible is washed with the boiling solvent and dried at $105^{\circ} \mathrm{C}$.

\section{COMPARISON OF METHODS}

The above methods were used in the determination of the foreign insoluble content in three specimens of shellac. The resulting data are given in Table 2 .

TABLE 2.-Content of insoluble matter determined by various methods

\begin{tabular}{|c|c|c|c|c|c|c|c|c|c|c|}
\hline & & \multicolumn{3}{|c|}{ Seed lac } & \multicolumn{3}{|c|}{ Flake shellac } & \multicolumn{3}{|c|}{$\begin{array}{l}\text { Bleached shellac } \\
\text { varnish }\end{array}$} \\
\hline \multirow[t]{2}{*}{ Method } & \multirow[t]{2}{*}{ Solvent } & \multicolumn{3}{|c|}{ Insoluble } & \multicolumn{3}{|c|}{ Insoluble } & \multicolumn{3}{|c|}{ Insoluble } \\
\hline & & A & B & $\begin{array}{c}\text { A ver- } \\
\text { age }\end{array}$ & A & B & $\begin{array}{c}\text { Aver- } \\
\text { age }\end{array}$ & A & B & $\begin{array}{l}\text { Aver- } \\
\text { age }\end{array}$ \\
\hline $\begin{array}{l}\text { A. S. T. M } \\
\text { U. S. S. I. A } \\
\text { Stillwell-..- }\end{array}$ & $\begin{array}{l}\text { Alcohol } \\
2 \text { parts alcohol, }\end{array}$ & $\begin{array}{l}P e r \\
\text { cent } \\
6.24 \\
6.05 \\
6.86\end{array}$ & $\begin{array}{l}\text { Per } \\
\text { cent } \\
6.26 \\
6.09 \\
7.08\end{array}$ & $\begin{array}{l}\text { Per } \\
\text { cent } \\
6.25 \\
6.07 \\
6.97\end{array}$ & $\begin{array}{l}\text { Per } \\
\text { cent } \\
3.34 \\
3.23 \\
3.08\end{array}$ & $\begin{array}{l}\text { Per } \\
\text { cent } \\
3.20 \\
3.12 \\
3.06\end{array}$ & \begin{tabular}{|} 
Per \\
cent \\
3.27 \\
3.18 \\
3.18
\end{tabular} & $\begin{array}{c}\text { Per } \\
\text { cent } \\
1.45 \\
1.48 \\
49\end{array}$ & $\begin{array}{l}P e r \\
\text { cent } \\
1.50 \\
1.44\end{array}$ & $\begin{array}{c}\text { Per } \\
\text { cent } \\
1.48 \\
1.46\end{array}$ \\
\hline Heated crucible & $\begin{array}{l}\text { tetrachloride. } \\
\text { Butanol } \\
\text { Cellosolve.................... }\end{array}$ & $\begin{array}{l}5.70 \\
5.66\end{array}$ & $\begin{array}{l}\text { 5. } 62 \\
\text { 5. } 72\end{array}$ & $\begin{array}{l}5.66 \\
5.69\end{array}$ & $\begin{array}{l}2.92 \\
2.87\end{array}$ & $\begin{array}{l}2.85 \\
2.92\end{array}$ & $\begin{array}{l}2.89 \\
2.90\end{array}$ & $\begin{array}{l}.25 \\
.36\end{array}$ & .29 & $\begin{array}{l}.27 \\
.32\end{array}$ \\
\hline
\end{tabular}

The differences in the results obtained by the various methods are doubtless due to $(a)$ the temperatures of the respective solvents while in contact with the filtering medium, $(b)$ differences in the

10 Replacing method for Determination of Matter Insoluble in Hot Alcohol on pp. 7 to 12 of Official Methods of Analysis; approved by United States Shellac Importers' Association (Inc.), and American Bleached Shellac Manufacturers' Association (Ino.), issued 1929 and effective on July 1, 1930.

11 A. G. Stillwell ,J. Ind. Eng. Chem., vol. 2, p. 420; 1930. 
solvent power of the respective solvents, $(c)$ efficiencies of the filtering mediums.

The temperatures of the various solvents during operation were recorded. In the continuous extraction methods the temperatures of the condensed alcohol and of the alcohol-carbon tetrachloride mixture varied from $2^{\circ}$ to $10^{\circ} \mathrm{C}$. below their respective boiling points. On the other hand, the temperatures of the butanol and cellosolve solutions in the heated crucible never fell below $80^{\circ} \mathrm{C}$. This temperature is well above the points at which the shellac wax starts to precipitate from these solutions. That the better results obtained with butanol or cellosolve were not entirely due to the higher temperature which was maintained in the heated crucible was shown by a number of experiments in which alcohol was used as the solvent. In these experiments the results were from 0.3 to 0.8 per cent high. The undissolved shellac wax was readily removed from the residues by means of either butanol or cellosolve.

The efficiencies of the different filter media were compared by carefully evaporating portions of the filtrates from each of these methods and making a microscopic examination of the residues. That from the Stillwell method showed an appreciable amount of fine insoluble matter and short cotton fibers. The residues from the American Society for Testing Materials and United States Shellac Importers' Association methods both showed small amounts of fine insoluble matter and paper fibers. No foreign matter of any description could be detected in the residue from the heated crucible method.

An unpublished investigation by $\mathrm{R}$. T. Mease at this bureau showed that a paper extraction thimble is capable of retaining 1 per cent by weight of alcohol even after prolonged heating at $105^{\circ}$ to $110^{\circ} \mathrm{C}$. However a glass-filter crucible containing a disk of filter paper which weighed approximately $55 \mathrm{mg}$. and an asbestos mat, when treated with either butanol or cellosolve and dried for one hour at $105^{\circ}$ to $110^{\circ} \mathrm{C}$., showed no appreciable gain in weight.

In view of all the above facts, the method of the United States Shellac Importers' Association appears to be the most satisfactory of the continuous extraction methods. However, it is not possible to attain with it as good accuracy and reproducibility as with the heated crucible method.

\section{EFFECT OF SAMPLING AND GRINDING}

Care must be taken to select a sample for analysis that will be representative of the shipment. Since certain types of shellac contain considerable foreign insoluble matter, every precaution should be taken that the sample is thoroughly mixed. The shellac sample should be carefully ground so as not to produce excessive heating. Even moderate heating renders some of the shellac insoluble.

The effect of the fineness of the shellac upon the reproducibility of results is shown in Table 3 . Portions of dry shellac samples passing a No. 30 sieve were reground to pass a No. 40 sieve, thoroughly rolled and mixed. Duplicate determinations were made with the heated crucible method with butanol as the solvent, and the results were compared with those obtained on the samples passing a No. 30 sieve. The data show that grinding to pass a No. 40 sieve yields slightly more concordant results, probably because of the more uniform sampling thereby secured. 
TABLE 3.-Effect of fineness

\begin{tabular}{|c|c|c|c|c|c|c|}
\hline \multirow{3}{*}{$\begin{array}{l}\text { Sieve through which all the sample passed } \\
\text { (B. S. sieve series) }\end{array}$} & \multicolumn{6}{|c|}{ Insoluble matter } \\
\hline & \multicolumn{6}{|c|}{ Sample No. } \\
\hline & 1 & 2 & 3 & 4 & 5 & 6 \\
\hline No. $30_{\ldots}$ & $\left\{\begin{array}{r}\text { Per cent } \\
3.73 \\
3.78\end{array}\right.$ & $\begin{array}{r}\text { Per cent } \\
2.62 \\
2.68\end{array}$ & $\begin{array}{r}\text { Per cent } \\
2.56 \\
2.65\end{array}$ & $\begin{array}{r}\text { Per cent } \\
1.44 \\
1.39\end{array}$ & $\begin{array}{r}\text { Per cent } \\
6.30 \\
6.45\end{array}$ & $\begin{array}{r}\text { Per cent } \\
5.53 \\
5.62\end{array}$ \\
\hline Average... & 3.76 & 2.65 & 2.61 & 1.42 & 6.38 & 5.58 \\
\hline No. $40 \ldots$ & $\begin{array}{l}3.80 \\
3.80\end{array}$ & $\begin{array}{l}2.68 \\
2.68\end{array}$ & $\begin{array}{l}2.55 \\
2.59\end{array}$ & $\begin{array}{l}1.40 \\
1.41\end{array}$ & $\begin{array}{l}6.43 \\
6.40\end{array}$ & $\begin{array}{l}5.44 \\
5.48\end{array}$ \\
\hline Average & 3.80 & 2.68 & 2.57 & 1.41 & 6.42 & 5.46 \\
\hline
\end{tabular}

\section{RECOMMENDED METHOD}

\section{DESCRIPTION}

(a) SOLVENTS

Either normal butyl alcohol (98 to 99 per cent) or ethylene glycolmono-ethyl-ether (98 to 99 per cent).
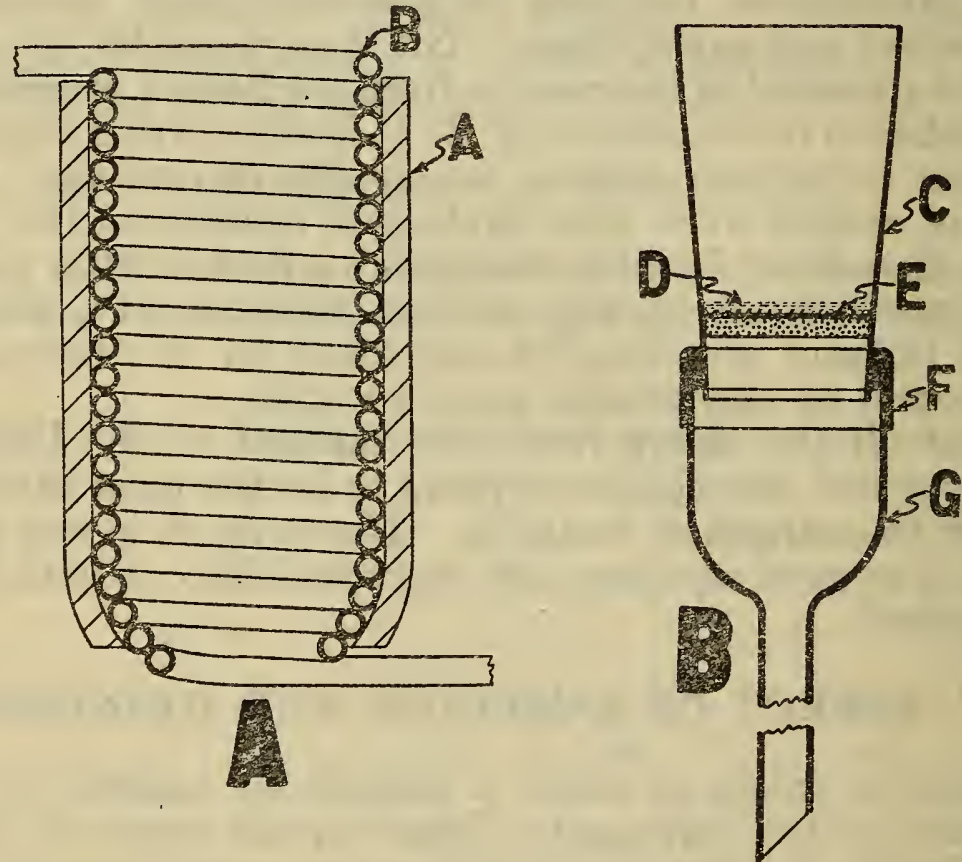

Figdre 1.-Apparatus used in the recommended method for the determination of insoluble matter in shellac

$A$-Heating unit, $a$, sheet asbestos; $b$, copper coil. $B-$ Filtering unit, $c$, filter crucible; $d$, asbestos mat; $e$, disk of filter paper; $f$, rubber tubing; $g$, carbon
filter funnel.

\section{(b) APPARATUS. (See fig. 1.)}

1. A Jena glass-filter crucible (c), (listed in Empire Laboratory Supply Co. (Inc.) catalogue as No. 8002, size No. 1), having a capacity of $30 \mathrm{ml}$, with a fritted-glass filter disk having a thickness of 3 $\mathrm{mm}$ and a porosity of " 5 to 7 " (average diameter of pores $35 \mu$ to $40 \mu$ ).

2. A carbon filter funnel $(g)$, made of pyrex glass, to fit the crucible. 
3. A heating coil (b) made of $3 \mathrm{~mm}$ copper tubing of such size and shape that the filter crucible and the large part of the carbon tube will fit snugly within it.

\section{(c) PROCEDURE}

Cut a disk of filter paper (e) (Whatman No. 41 or equivalent) to fit inside the crucible and place it on top of the glass filter. Introduce upon the filter paper, in the customary manner, an asbestos mat $(d)$ approximately $3 \mathrm{~mm}$ in thickness. Dry the crucible to constant weight at $105^{\circ}$ to $110^{\circ} \mathrm{C}$. and cool in a desiccator.

Weigh the prepared crucible and place it within the carbon tube, using thin rubber tubing $(f)$ to form an air-tight connection. Place the combined filtering unit $(B)$ within the heating unit $(A)$, which is insulated on the outside with sheet asbestos $(a)$, attach to a suction flask, and pass a current of steam through the coil.

Accurately weigh approximately $5 \mathrm{~g}$ of the dry shellac (or sufficient shellac varnish to contain about $5 \mathrm{~g}$ of nonvolatile matter) into a $200 \mathrm{ml}$ beaker. Add $75 \mathrm{ml}$ of the solvent and bring the solution to boiling on an electric stove. Kieep the solution boiling slowly for five minutes to insure complete solution. Pour about 10 $\mathrm{ml}$ of the boiling solvent from a wash bottle into the heated crucible. Apply gentle suction and immediately pour the boiling shellac solution into the crucible in such a manner as to retain as much as possible of the insoluble residue in the beaker. Wash the insoluble residue successively with three $20 \mathrm{ml}$ portions of the solvent, boiling the solution on the clectric stove for about one minute before each filtration. Finally, transfer the residue from the beaker to the crucible with a stream of the boiling solvent from a wash bottle, using a "policeman" when necessary. Wash down the inner walls of the crucible with the boiling solvent. The total volume of the solvent used should be approximately $175 \mathrm{ml}$. It is advisable to keep the crucible covered with a small watch glass at all times, except when actually transferring the solution from the beaker to the crucible, or when washing down the inside walls of the crucible. By this procedure a higher temperature is maintained within the crucible.

Allow the crucible to remain within the heating coil with the suction on for a few minutes, so as to suck it as dry as possible. Remove the crucible, wash the outside with boiling solvent, and dry it in an oven at $105^{\circ}$ to $110^{\circ} \mathrm{C}$. for one hour, cool in a desiccator, and weigh. From the weight of the residue and the weight of the sample compute the percentage of insoluble matter.

The insoluble matter can be easily removed, together with the asbestos mat and filter paper. The crucible may be used several times without further cleaning. When additional cleaning is necessary, it may be easily accomplished by immersing the crucible in a hot mixture of sulphuric and nitric acids for a few minutes.

\section{TYPICAL RESULTS}

Several samples of dry orange shellac and bleached shellac were secured through the courtesy of J. W. Paisley and William H. Gardner, of the United States Shellac Importers' Association. In addition, two samples of bleached shellac varnish and one sample of orange shellac varnish were analyzed. These specimens were con-

$$
84614-31-7
$$


sidered to be sufficiently diversified in their contents of insoluble matter to test the reliability and adaptability of the recommended method. These specimens were analyzed by the continuous-extraction method of the United States Shellac Importers' Association and the recommended method. The data are compiled in Table 4.

TABLE 4.-Per cent of insoluble matter as determined by old and new methods

\begin{tabular}{|c|c|c|c|c|c|c|c|c|c|}
\hline $\begin{array}{l}\text { Test } \\
\text { sample } \\
\text { No. }\end{array}$ & Type of material & Analyst & $\begin{array}{l}\text { U.S.S. } \\
\text { I. A. } \\
\text { method } \\
\text { using } \\
\text { alcohol }\end{array}$ & $\begin{array}{l}\text { A ver- } \\
\text { age }\end{array}$ & $\begin{array}{c}\text { Recom- } \\
\text { mended } \\
\text { method } \\
\text { using } \\
\text { butanol }\end{array}$ & $\begin{array}{l}\text { A ver- } \\
\text { age }\end{array}$ & $\begin{array}{c}\text { Recom- } \\
\text { miended } \\
\text { method } \\
\text { using } \\
\text { cello- } \\
\text { solve }\end{array}$ & $\begin{array}{c}\text { A ver- } \\
\text { age }\end{array}$ & $\begin{array}{l}\text { Aver- } \\
\text { age } \\
\text { differ- } \\
\text { ences } \\
\text { old } \\
\text { minus } \\
\text { new } \\
\text { meth- } \\
\text { ods }\end{array}$ \\
\hline $1 \ldots$ & Orange flake shellac (T. N.) - & $\left\{\begin{array}{l}a_{---} \\
a_{---} \\
b_{---} \\
c_{---}\end{array}\right.$ & $\begin{array}{l}4.12 \\
4.25 \\
4.16 \\
3.48\end{array}$ & 4.00 & $\begin{array}{l}3.73 \\
3.78 \\
3.58 \\
3.62\end{array}$ & 3.68 & $\begin{array}{r}3.78 \\
3.72 \\
\hdashline-1\end{array}$ & 3.75 & 0.33 \\
\hline 2. & $\left\{\begin{array}{l}\text { Orange flake shellac (Ralli } \\
\text { U. S. S.I. A., T. N.) }\end{array}\right.$ & $\left\{\begin{array}{l}a_{-.-} \\
a_{---} \\
b_{-.} \\
c_{--.}\end{array}\right.$ & $\begin{array}{l}2.90 \\
3.00 \\
2.60 \\
2.65\end{array}$ & 2.79 & $\begin{array}{l}2.68 \\
2.63 \\
2.61 \\
2.64\end{array}$ & 2. 64 & $\mid \begin{array}{r}2.63 \\
2.70 \\
-2 .--\end{array}$ & 2.66 & .14 \\
\hline 3 & $\left\{\begin{array}{l}\text { Orange fiake shellac (N. M. } \\
\text { I., U. S. S. I. A., T. N.) }\end{array}\right.$ & $\left\{\begin{array}{l}a_{-.} \\
a_{--} \\
b_{--} \\
c_{--}\end{array}\right.$ & $\begin{array}{l}2.80 \\
2.88 \\
2.87 \\
2.82\end{array}$ & 2.84 & $\begin{array}{l}2.56 \\
2.65 \\
2.56 \\
2.65\end{array}$ & 2.58 & $\begin{array}{r}2.54 \\
2.57 \\
-\end{array}$ & 2. 56 & .27 \\
\hline 4. & $\left\{\begin{array}{l}\text { Orange flake shellac (G. R. } \\
\text { P. Superfine) }\end{array}\right.$ & $\left\{\begin{array}{l}a_{-.-} \\
a_{---} \\
b_{---} \\
c_{---}\end{array}\right.$ & $\begin{array}{l}1.75 \\
1.50 \\
1.53 \\
1.44\end{array}$ & 1.56 & $\begin{array}{l}1.44 \\
1.39 \\
1.35 \\
1.44\end{array}$ & 1.40 & $\begin{array}{r}1.37 \\
1.41 \\
\hdashline-1 .-\end{array}$ & 1.39 & .16 \\
\hline 5 & $\left\{\begin{array}{c}\text { Seed lac (E. D. S. Co. } \\
\text { Blosky) }\end{array}\right.$ & $\left\{\begin{array}{l}a_{--} \\
a_{--} \\
b_{--} \\
c . .\end{array}\right.$ & $\begin{array}{l}6.65 \\
6.80 \\
6.20 \\
5.37\end{array}$ & 6.25 & $\begin{array}{l}6.45 \\
6.30 \\
6.35 \\
6.14\end{array}$ & 6.31 & \begin{tabular}{r}
6.36 \\
6.40 \\
\hdashline..-- \\
-2
\end{tabular} & 6.38 & -.06 \\
\hline 6 & Seed lac (L. \& M. Bysacki) - & $\left\{\begin{array}{l}a_{-.} \\
\mathrm{a}_{--} \\
\mathrm{b}_{--} \\
\mathrm{c}_{--}\end{array}\right.$ & $\begin{array}{l}5.80 \\
5.65 \\
5.34 \\
4.75\end{array}$ & 5.38 & $\begin{array}{l}5.53 \\
5.62 \\
5.38 \\
5.19\end{array}$ & 5.43 & $\begin{array}{r}5.54 \\
5.44 \\
-\end{array}$ & 5.49 & -.05 \\
\hline $7-\ldots$ & Dry bleached shellac..- & $\left\{\begin{array}{l}a_{--} \\
a_{--} \\
b_{--} \\
c_{--}\end{array}\right.$ & $\begin{array}{l}.57 \\
.40 \\
.34 \\
.41\end{array}$ & .43 & $\begin{array}{l}.06 \\
.04 \\
.08\end{array}$ & .06 & $\begin{array}{r}.04 \\
.09 \\
-.-- \\
-.--\end{array}$ & .07 & .37 \\
\hline 8. & - & $\left\{\begin{array}{l}\mathrm{a}_{-.} \\
\mathrm{a}_{--} \\
\mathrm{b}_{-.} \\
\mathrm{c}_{-.}\end{array}\right.$ & $\begin{array}{l}.63 \\
.49 \\
.50 \\
.45\end{array}$ & .52 & $\begin{array}{l}.05 \\
.05 \\
.06\end{array}$ & .05 & 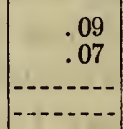 & .08 & .45 \\
\hline $\begin{array}{ll}9 \\
10 \\
11 \\
11\end{array}$ & $\begin{array}{l}\text { Bleached shellac varnish } \\
\text { Test sample No. } 3 \text { made } \\
\text { into varnish (4 pounds to } 1 \\
\text { gallon of alcohol) }\end{array}$ & a & $\begin{array}{r}.97 \\
1.02\end{array}$ & 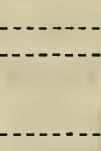 & $\begin{array}{l}.31 \\
.47\end{array}$ & -- & $\begin{array}{l}.34 \\
.47\end{array}$ & - & $\begin{array}{l}.64 \\
.55\end{array}$ \\
\hline
\end{tabular}

a. Author

b. Analysts working in independent laboratories.

\section{CONCLUSIONS}

All of the methods of the continuous extraction type require care and attention to the details of operation, even under the most favorable conditions. They consume considerable time and may give erroneous results. The chief sources of error are $(a)$ incomplete solubility of the shellac wax in alcohol, $(b)$ possible loss of insoluble matter from the filter medium, and $(c)$ retention of some of the solvent 
in the filter medium. The United States Shellac Importers Association method was found to be the most satisfactory of the methods of this type.

The resinous constituent of shellac is completely soluble in both butanol and cellosolve. The shellac wax is held in solution by either of these solvents at a much lower temperature than by alcohol.

As butanol holds the shellac wax in solution at a lower temperature than does cellosolve, it is a slightly better solvent. However, butanol is more disagreeable to work with than is cellosolve. Either of these solvents can be used with the assurance of obtaining accurate results.

The materials should be carefully samples and ground to pass a No. 40 sieve.

The heated-crucible method yields more concordant and more accurate results than the present standard methods.

The recommended method is applicable to all types of lac resins.

\section{ACKNOWLEDGMENTS}

The author wishes to express his appreciation to the United States Shellac Importers Association; to J. W. Paisley, of Gillespie-RogersPyatt Co. (Inc.), and W. H. Gardner, of the Shellac Research Bureau, for the courtesy extended in preparing the samples and their cooperation; and to P. H. Walker, who directed this investigation.

Washington, September 17, 1931. 